\title{
Dynamic Response and Fuzzy Control of Half-Car High-Speed Train and Bridge Interaction
}

\author{
Mehmet Akif KOÇ \\ Sakarya Applied Sciences University, Technology Faculty Mechatronics Engineering, Sakarya, Turkey
}

\begin{abstract}
In this study, the interaction between 10-DOF half-car high-speed train (HST) and bridge has been introduced with active suspension system (ASS) placed on primary and secondary system of the HST. The bridge has been modelled according to Euler-Bernoulli beam theory considering simple-supported boundary conditions. The train model consists of front and rear bogies, body masses. To connect any mass to each other the spring and damping element have been used. The equation of motion of the entire system has been determined using Lagrange equation in the time domain. The excessive vibration due to train bridge interaction (TBI) is analyzed then fuzzy logic control algorithm has been designed to control these uncomfortable vibrations. Consequently, the vibrations on the train body, front and rear bogie is reduced significantly.
\end{abstract}

Key words: Fuzzy logic controller, high-speed train, active control, vibration analysis.

\section{Introduction}

The improvement and dissemination of HST transportation causes a leading role in promoting economic progress, prosperity and cultural contact in countries. But, as the operating speeds of the HSTs increase, the vibrations in the vehicle components, which negatively affect passenger comfort and transportation safety, increase considerably as well. Therefore, reducing and controlling the vibrations in the train components is very significant for passenger comfort, rail holding and riding safety $[1,2]$.

The TBI is very important problem in engineering because of a heavy vehicle such as HST moving on the flexible structures like bridge beam causes excessive vibrations due to TBI. Because in such a system, the train and the bridge are designed as two different subsystems, and the dynamic response of these two different subsystems is affected by each other through the movement of the train on the bridge [3,4]. With the developments in computer capacity and appearance of highcapacity computers, studies were launched on complicated simulations which take into consideration the bridge and train dynamics together [5-7].

Vibration reducing on TBI models can be obtained using new technical improvements with much little cost or results. For instance, a suspension system with self-adjusting capabilities can quite develop the performance of a train system on the track irregularity cases. Besides, the same

*Corresponding author: Address: Faculty of Engineering, Department of Civil Engineering Sakarya University, 54187, Sakarya TURKEY. E-mail address: caglar@sakarya.edu.tr, Phone: +902642955752 
technique would be used to approach to a train model with minimum impacts on track and bridges [8] On the other hand, if a flexible system like a bridge is threatened by the vibrational effects, passive or active techniques in structural control would be used to increase its reliability and its durability $[9,10]$. Conventional passive suspension systems are not capable of the improvement of high-speed train with the accelerating of the railway speed. The semi-active suspension of vehicles uses the damping components that can be controlled and the closed loop control system [11-14], which can regulate the damping force according to the feedback signals generated by the lateral acceleration of the car body, so that the damping suspension stay in the best condition and improve the stability of high-speed train. Therefore, well-designed semi-active suspension system is an effective approach to decrease the vibration of the vehicle and improve the vehicle's stability.

In this study, an active suspension system with fuzzy logic controller has been modelled to reduce excessive vibrations occurred on the train component such as train body, front and rear bogies. With the proposed the method given in this study, the interaction between flexible structures and moving vehicles is analyzed easily without the need for costly and time-consuming experimental studies.

\section{Mathematical Formulation}

In the mathematical formulation, 10-DOF half car HST model is considered with active suspension system as shown in Figure 1. The train moves on the bridge beam from the left side of the bridge to right side until all wheelset axles pass to bridge. The train model considered as single car moving on the bridge beam with constant train velocity v. Moreover, the train and bridge parameters used in this study given by Tables 1 and 2 .

\subsection{TBI Model with ASS}

In this study, the physical model shown in Fig. 1 is taken into consideration to reduce the disturbing vibrations caused by train-bridge interaction using AVC. In Table 1 and 2, a description of the parameters used in this study and the values of these parameters are given respectively.

In the formulation for the TBI analysis the following assumptions will be adopted:

- As shown in Fig. 1, the train model is modeled as a 10-DOF half-car model, which generally consists of front-rear bogies, wheels, train body, secondary suspension element connecting the train body and bogies, and primary suspension elements connecting bogies and wheels.

- The rails over which the train passes are thought to be integrated with the bridge beam and its strength is added to the bridge beam for calculation.

- The velocity of the HST car is constant.

With these assumptions, the kinetic and potential energy of the vehicle-bridge interaction, as shown in Fig. 1, is expressed as follows respectively: 
$E_{k}=\frac{1}{2}\left(\int_{0}^{L} \mu\left[\dot{w}_{b}^{2}(x, t)\right] d x+\left\{\begin{array}{l}m_{c} \dot{r}_{1}^{2}+I_{c} \dot{r}_{2}^{2}+m_{b 1} \dot{r}_{3}^{2}+I_{b 1} \dot{r}_{4}^{2}+m_{b 2} \dot{r}_{5}^{2}+ \\ I_{b 2} \dot{r}_{6}^{2}+m_{w 1} \dot{r}_{7}^{2}+m_{w 2} \dot{r}_{8}^{2}+m_{w 3} \dot{r}_{9}^{2}+m_{w 4} \dot{r}_{10}^{2}\end{array}\right\}\right)$,

Table 1

Nomenclature of vehicle and bridge parameters.

\begin{tabular}{clcl}
\hline \multicolumn{1}{c}{ Parameters } & \multicolumn{2}{c}{ Subscripts } \\
\hline$r$ & Vertical or angular coordinates & $c$ & Body \\
$c$ & Damper's Coefficients & $w$ & Primary suspension and wheels \\
$m$ & Mass & $v$ & Secondary suspension \\
$k$ & Spring's Stiffness Coefficient & $b$ & Bridge \\
$l$ & Distance between train body center and bogie center & $r$ & Wheel stiffness and damping \\
$d$ & Distance between bogie center and wheel & & \\
$U$ & Actuator's force & & \\
\hline
\end{tabular}

Table 2

The properties of train and bridge models

\begin{tabular}{ll}
\hline Train parameters & \\
\hline Train body mass $\left(m_{c}\right)$ & $41.75 \mathrm{ton}$ \\
Front and rear bogie masses $\left(m_{b 1}=m_{b 2}\right)$ & $3.04 \mathrm{ton}$ \\
Mass of wheels $\left(m_{w 1}=m_{w 2}=m_{w 3}=m_{w 4}\right)$ & $1.78 \mathrm{ton}$ \\
Mass moment of Inertia of train body $\left(I_{c}\right)$ & $2080 \mathrm{ton} \mathrm{m}{ }^{2}$ \\
Mass moment of Inertia of front and rear bogies $\left(I_{b l}=I_{b 2}\right)$ & $3.93 \mathrm{ton} \mathrm{m}{ }^{2}$ \\
Stiffness of primary suspension system $\left(k_{v l}=k_{v 2}\right)$ & $1180 \mathrm{kN} / \mathrm{m}$ \\
Stiffness of secondary suspension system $\left(k_{w l}=k_{w 2}=k_{w 3}=k_{w 4}\right)$ & $530 \mathrm{kN} / \mathrm{m}$ \\
Damping of primary suspension system $\left(c_{v l}=c_{v 2}\right)$ & $39.2 \mathrm{kNs} / \mathrm{m}$ \\
Damping of secondary suspension system $\left(c_{w l}=c_{w 2}=c_{w 3}=c_{w 4}\right)$ & $90.2 \mathrm{kNs} / \mathrm{m}$ \\
Half of longitudinal distance between centers of gravity of front & $8.75 \mathrm{~m}$ \\
and rear bogies $\left(l_{l}=l_{2}\right)$ & \\
Longitudinal distance between centers of gravity of front and & $1.25 \mathrm{~m}$ \\
rear bogies and nearest side of bogies $\left(d_{l}=d_{2}=d_{3}=d_{4}\right)$ & \\
\hline Bridge parameters & \\
\hline Elasticity module $(E)$ & $207 \mathrm{GPa}$ \\
Bridge length $(L)$ & $50 \mathrm{~m}$ \\
Cross section inertia moment $(I)$ & $0.174 \mathrm{~m} 4$ \\
Mass of unit length of bridge $(\mu)$ & $20 \mathrm{t} / \mathrm{m}$ \\
Bridge equivalent damping coefficient $(c)$ & $1750 \mathrm{Ns} / \mathrm{m}$ \\
\hline
\end{tabular}

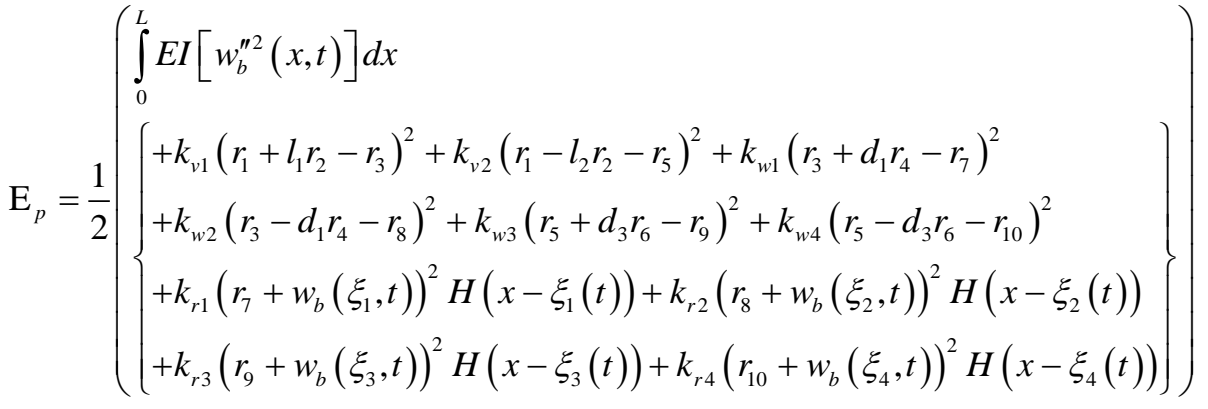

Rayleigh dissipation function for the train-bridge integrated system is expressed as follows: 
$\mathrm{D}=\frac{1}{2}\left\{\begin{array}{l}\int_{0}^{L} c \dot{w}_{b}^{2}(x, t) d x+c_{v 1}\left(\dot{r}_{1}+l_{1} \dot{r}_{2}-\dot{r}_{3}\right)^{2}+c_{v 2}\left(\dot{r}_{1}-l_{2} \dot{r}_{2}-\dot{r}_{5}\right)^{2}+c_{w 1}\left(\dot{r}_{3}+d_{1} \dot{r}_{4}-\dot{r}_{7}\right)^{2} \\ +c_{w 2}\left(\dot{r}_{3}-d_{1} \dot{r}_{6}-\dot{r}_{8}\right)^{2}+c_{w 3}\left(\dot{r}_{5}+d_{3} \dot{r}_{6}-\dot{r}_{9}\right)^{2}+c_{w 4}\left(\dot{r}_{5}-d_{3} \dot{r}_{6}-\dot{r}_{10}\right)^{2} \\ +c_{r 1}\left(\dot{r}_{7}+\dot{w}_{b}\left(\xi_{1}, t\right)\right)^{2} H\left(x-\xi_{1}(t)\right)+c_{r 2}\left(\dot{r}_{8}+\dot{w}_{b}\left(\xi_{2}, t\right)\right)^{2} H\left(x-\xi_{2}(t)\right) \\ +c_{r 3}\left(\dot{r}_{9}+\dot{w}_{b}\left(\xi_{3}, t\right)\right)^{2} H\left(x-\xi_{3}(t)\right)+c_{r 4}\left(\dot{r}_{10}+\dot{w}_{b}\left(\xi_{4}, t\right)\right)^{2} H\left(x-\xi_{4}(t)\right)\end{array}\right\}$,

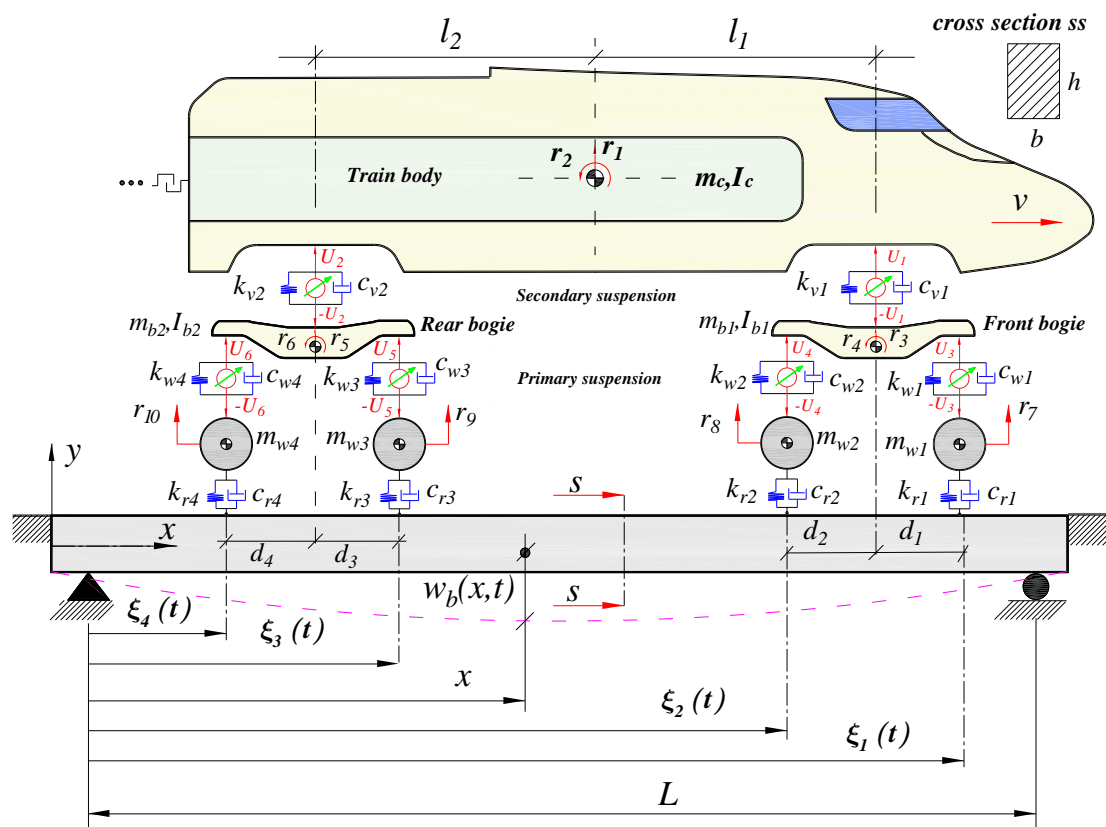

Figure 1. Physical model of TBI with ASS.

In Eq. (3), $c$ is the equivalent viscous damping coefficient for the beam. In addition, the Lagrangian $\left(L=E_{k}-E_{p}\right)$ of the system is equal to the difference between the kinetic energy and the potential energy. When the Lagrange equations are rearranged for HST with ten independent coordinates, the following is obtained:

$$
\begin{aligned}
& \frac{\mathrm{d}}{\mathrm{d} t}\left(\frac{\partial L}{\partial \dot{p}_{k}(t)}\right)-\frac{\partial L}{\partial p_{k}(t)}+\frac{\partial D}{\partial \dot{p}_{k}(t)}=U_{k}, k=1,2, \ldots ., 10, \\
& \frac{\mathrm{d}}{\mathrm{d} t}\left(\frac{\partial L}{\partial \dot{\eta}_{i}(t)}\right)-\frac{\partial L}{\partial \eta_{i}(t)}+\frac{\partial D}{\partial \dot{\eta}_{i}(t)}=Q_{i}, \quad \mathrm{i}=1,2,3,4,
\end{aligned}
$$

The motion equation of the train car with ten degrees of freedom and bridge model shown in Fig. 1 is obtained by using the orthogonality condition and the Galerkin approximation given by [15]. The motion equations for the train car body, front and rear bogies are expressed using the accelerations of the each DOF $r_{i}$, respectively, as follows: 


$$
\begin{aligned}
\ddot{r}_{1}= & \frac{-k_{v 1}}{m_{c}}\left(r_{1}+l_{1} r_{2}-r_{3}\right)-\frac{k_{v 2}}{m_{c}}\left(r_{1}-l_{2} r_{2}-r_{5}\right)-\frac{c_{v 1}}{m_{c}}\left(\dot{r}_{1}+l_{1} \dot{r}_{2}-\dot{r}_{3}\right) \\
& -\frac{c_{v 2}}{m_{c}}\left(\dot{r}_{1}-l_{1} \dot{r}_{2}-\dot{r}_{5}\right)+\mathrm{U}_{1}+\mathrm{U}_{2}, \\
\ddot{r}_{3}= & \frac{k_{v 1}}{m_{b 1}}\left(r_{1}+l_{1} r_{2}-r_{3}\right)-\frac{k_{w 1}}{m_{b 1}}\left(r_{3}+d_{1} r_{4}-r_{7}\right)-\frac{k_{w 2}}{m_{b 1}}\left(r_{3}-d_{1} r_{4}-r_{8}\right) \\
& +\frac{c_{v 1}}{m_{b 1}}\left(\dot{r}_{1}+l_{1} \dot{r}_{2}-\dot{r}_{3}\right)-\frac{c_{w 1}}{m_{b 1}}\left(\dot{r}_{3}+d_{1} \dot{r}_{4}-\dot{r}_{7}\right)-\frac{c_{w 2}}{m_{b 1}}\left(\dot{r}_{3}-d_{1} \dot{r}_{4}-\dot{r}_{8}\right)-\frac{\mathrm{U}_{1}+\mathrm{U}_{3}+\mathrm{U}_{4},}{m_{b 1}} \\
\ddot{r}_{5}= & \frac{k_{v 2}}{m_{b 2}}\left(r_{1}-l_{2} r_{2}-r_{5}\right)-\frac{k_{w 3}}{m_{b 2}}\left(r_{5}+d_{3} r_{6}-r_{9}\right)-\frac{k_{w 4}}{m_{b 2}}\left(r_{5}-d_{3} r_{6}-r_{10}\right) \\
& +\frac{c_{v 2}}{m_{b 2}}\left(\dot{r}_{1}-l_{2} \dot{r}_{2}-\dot{r}_{5}\right)-\frac{c_{w 3}}{m_{b 2}}\left(\dot{r}_{5}+d_{3} \dot{r}_{6}-\dot{r}_{9}\right)-\frac{c_{w 4}}{m_{b 2}}\left(\dot{r}_{5}-d_{3} \dot{r}_{6}-\dot{r}_{10}\right)-\frac{U_{2}+U_{5}+U_{6}}{m_{b 2}},
\end{aligned}
$$

The response of the bridge beam, in the form of $n$ second order differential equations, are expressed as follows:

$$
\begin{aligned}
& N_{i} \ddot{\eta}_{i}(t)+c \varphi_{i}^{2}(x) \dot{\eta}_{i}(t)+S_{i} \eta_{i}(t)+\varphi_{i}\left(\xi_{1}(t)\right)\left\{f_{g 1}+k_{w 1}\left[\mathrm{r}_{7} \mathrm{D}_{1}-\mathrm{d}_{1} r_{4}-r_{3}\right]+c_{w 1}\left[\dot{r}_{7} D_{1}-d_{1} \dot{r}_{4}-\dot{r}_{3}\right]\right\} D_{1} \\
& +\varphi_{i}\left(\xi_{2}(t)\right)\left\{f_{g 2}+k_{w 2}\left[\mathrm{r}_{8} \mathrm{D}_{2}+\mathrm{d}_{1} r_{4}-r_{3}\right]+c_{w 2}\left[\dot{r}_{8} D_{2}+d_{1} \dot{r}_{4}-\dot{r}_{3}\right]\right\} D_{2} \\
& +\varphi_{i}\left(\xi_{3}(t)\right)\left\{f_{g 3}+k_{w 3}\left[\mathrm{r}_{9} \mathrm{D}_{3}-\mathrm{d}_{3} r_{6}-r_{5}\right]+c_{w 3}\left[\dot{r}_{9} D_{3}-d_{3} \dot{r}_{6}-\dot{r}_{5}\right]\right\} D_{3} \\
& +\varphi_{i}\left(\xi_{4}(t)\right)\left\{f_{g 4}+k_{w 4}\left[\mathrm{r}_{10} \mathrm{D}_{4}+\mathrm{d}_{3} r_{6}-r_{5}\right]+c_{w 4}\left[\dot{r}_{10} D_{4}+d_{3} \dot{r}_{6}-\dot{r}_{5}\right]\right\} D_{4}, i=1,2,3,4
\end{aligned}
$$

\subsection{Fuzzy Logic Controller}

In this study, the fuzzy logic controller given by Figure 2 has been used for suppressing of vibration on the HST's components such as train body, front and rear bogies. In this context, train body, front bogie and rear bogie vertical displacement parameters $r_{1}, r_{3}, r_{5}$ are chosen for the measured parameters. On the other hand, the references inputs are defined as parameters $R_{1}, R_{2}$ and $R_{3}$. Then, the errors of the controller have been amputated using these references inputs. After the derivation of these error parameters, the parameters error and derivation of the error has been defined as inputs for fuzzy logic controller used in this study. Figures 3a-c show three different fuzzy controller schemas for train body, front and rear bogies respectively. In the Figures 3a-c, input and output parameters of the fuzzy logic controller used in this paper are seen clearly. The parameters error and deviation of the error are defined as inputs for controller on the other hand the output parameter is determined as force of the active suspension system placed primary and secondary suspension systems respectively. The primary suspension system is the between train bogies and train wheelsets. The function of the primary suspension system is to dampen vibrations occurring contact point between bogie wheel and rail. Also, secondary suspension system has been placed between train body and front and rear bogies as shown in Figure 1. Similarly, primary suspension 
system, the secondary suspension system prevents vibration that occur between bogies and train body. The fuzzy logic controller generates the force of the actuators. Then these forces have been added equation of motion given in Equation (5a-c).

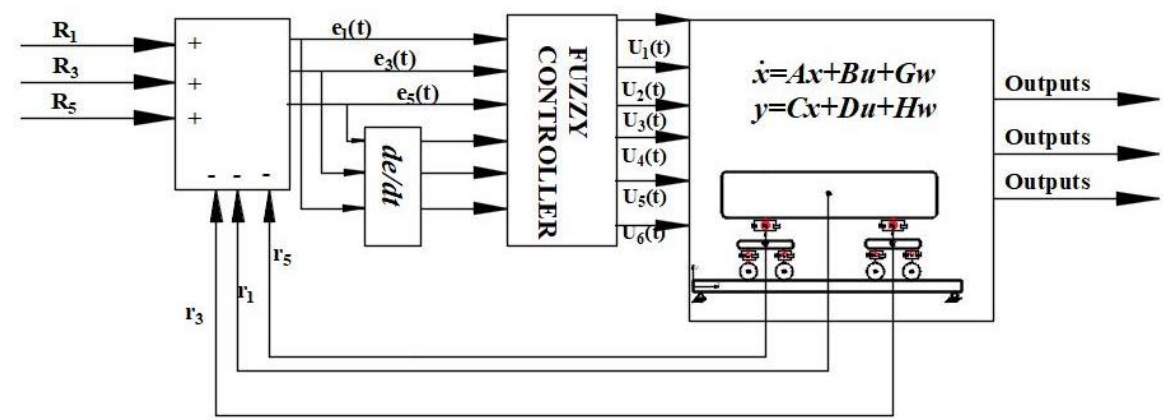

Figure 2. The fuzzy logic controller used in this study.

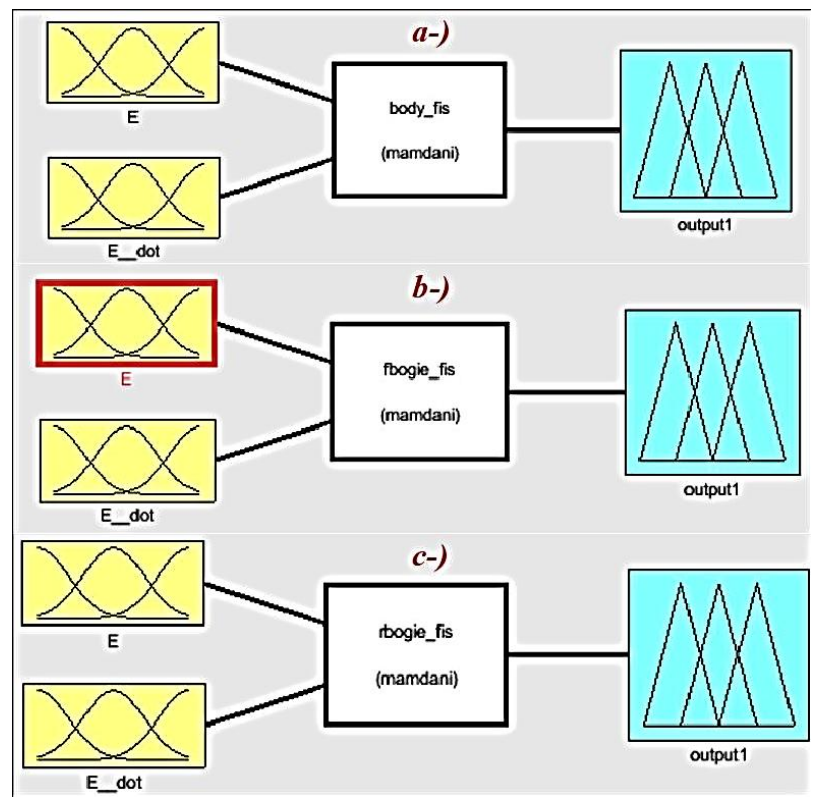

Figure 3. The input and output parameters for fuzzy logic controller used in this study.

Figure 4 show s membership functions of the fuzzy logic controller used in this study. As shown in figures, the input parameter error has been represented by five numbers membership functions. On the other hand, the input parameter deviation of the error has been presented by three membership functions. The output parameter actuator force is represented by nine number member ship functions. The all membership functions are selected as triangular geometry.

\section{Results}

Figure 5 shows relationships between input and output parameters. Figure 6 shows train body vertical displacement and acceleration for train and bridge parameters given in Table 1 considering HST's constant velocity $v=20 \mathrm{~m} / \mathrm{s}$. As shown in figure, the maximum train body vertical 
displacement has been defined as $37.7 \mathrm{~mm}$ in the case of without control. In the fuzzy control case, this value is obtained as $3.8 \mathrm{~mm}$. The train body vertical maximum displacement was reduced by approximately 90 percent. Similarly, as shown in the Figure 6b, the maximum train body vertical acceleration is determined as $0.3018 \mathrm{~m} / \mathrm{s}^{2}$ in the case of without control algorithm. In the case of with fuzzy logic control, this value is identified as $0.023 \mathrm{~m} / \mathrm{s}^{2}$. The maximum train body vertical

Table 2. Fuzzy laws used in controller.

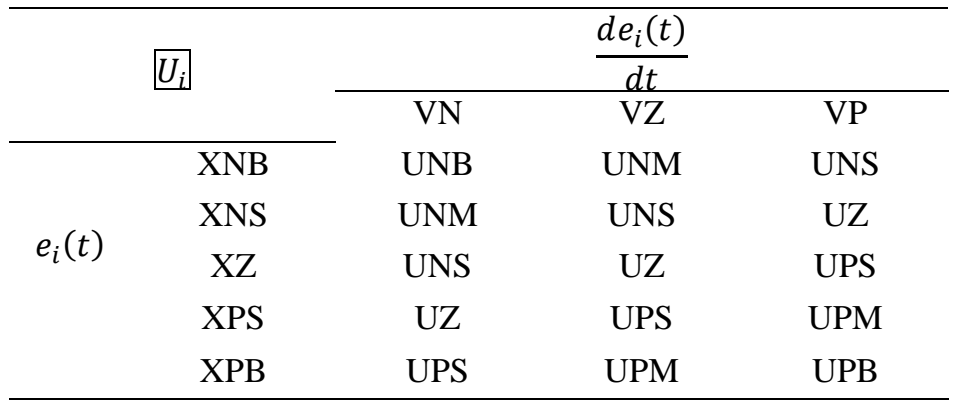
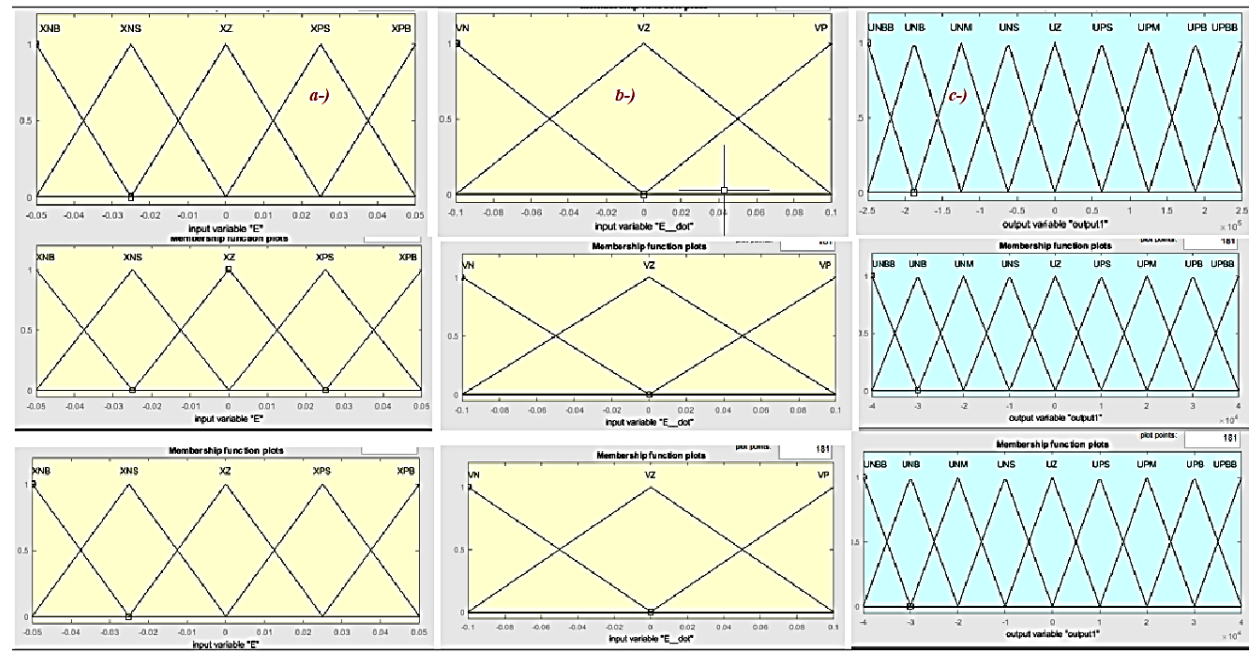

Figure 4. The membership functions of input and output parameters.

acceleration has been reduced about 92 percent. Figure 7a-b shows train front bogie vertical displacement and acceleration for train and bridge parameters given in Table 1 considering HST's constant velocity $v=20 \mathrm{~m} / \mathrm{s}$ respectively. As shown in figure, the maximum train front bogie vertical displacement has been defined as $33.02 \mathrm{~mm}$ in the case of without control. In the fuzzy control case, this value is obtained as $17.7 \mathrm{~mm}$. The train front bogie vertical maximum displacement was reduced by approximately 46 percent. Similarly, as shown in the Figure $7 b$, the maximum train front bogie vertical acceleration is determined as $0.2 \mathrm{~m} / \mathrm{s}^{2}$ in the case of without control algorithm. In the case of with fuzzy logic control, this value is identified as $0.1088 \mathrm{~m} / \mathrm{s}^{2}$. The maximum train front bogie vertical acceleration has been reduced about 50 percent. Figure 8a-b shows train rear bogie vertical displacement and acceleration for train and bridge parameters given in Table 1 considering HST's constant velocity $v=20 \mathrm{~m} / \mathrm{s}$ respectively. As shown in figure, the maximum train rear bogie vertical displacement has been defined as $35.83 \mathrm{~mm}$ in the case of without control. In 
the fuzzy control case, this value is obtained as $17.07 \mathrm{~mm}$. The train rear bogie vertical maximum displacement was reduced by approximately 50 percent. Similarly, as shown in the Figure $8 b$, the maximum train front bogie vertical acceleration is determined as $0.2364 \mathrm{~m} / \mathrm{s}^{2}$ in the case of without control algorithm. In the case of with fuzzy logic control, this value is identified as $0.1288 \mathrm{~m} / \mathrm{s}^{2}$. The maximum train front bogie vertical acceleration has been reduced about 48 percent. Besides, Figure 8 shows output of the fuzzy logic controller for all actuator placed on the HST model.
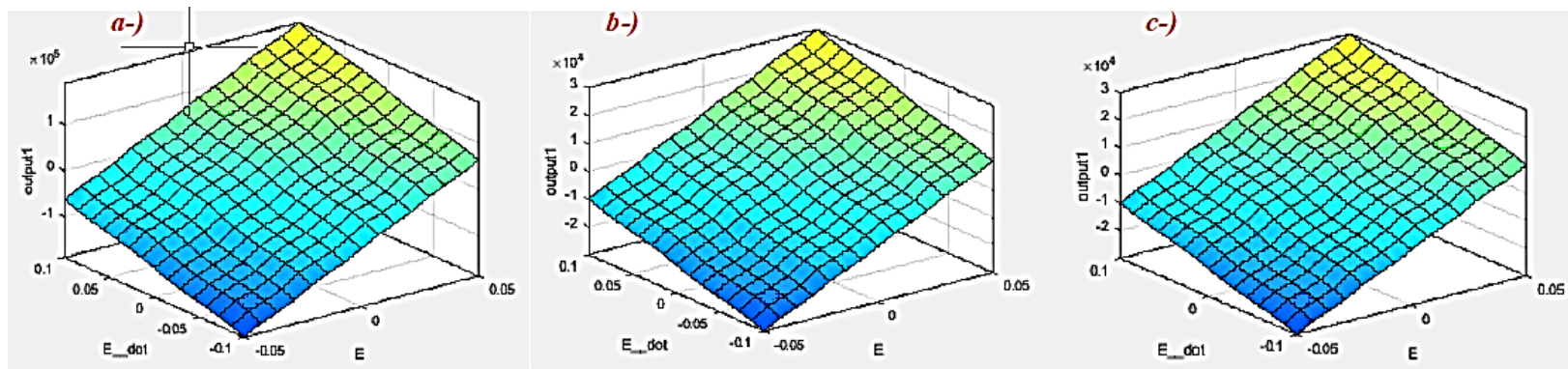

Figure 5. The output surface according to input parameters.
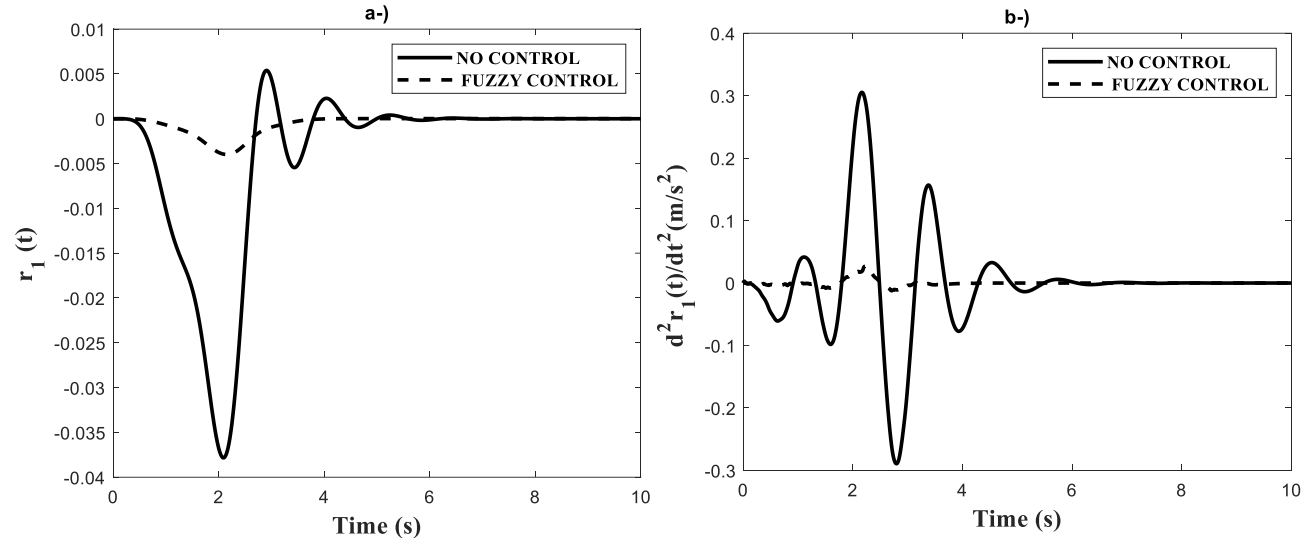

Figure 6. The train body vertical vibration with control and without control a-) train body vertical displacements b-) train body vertical acceleration.
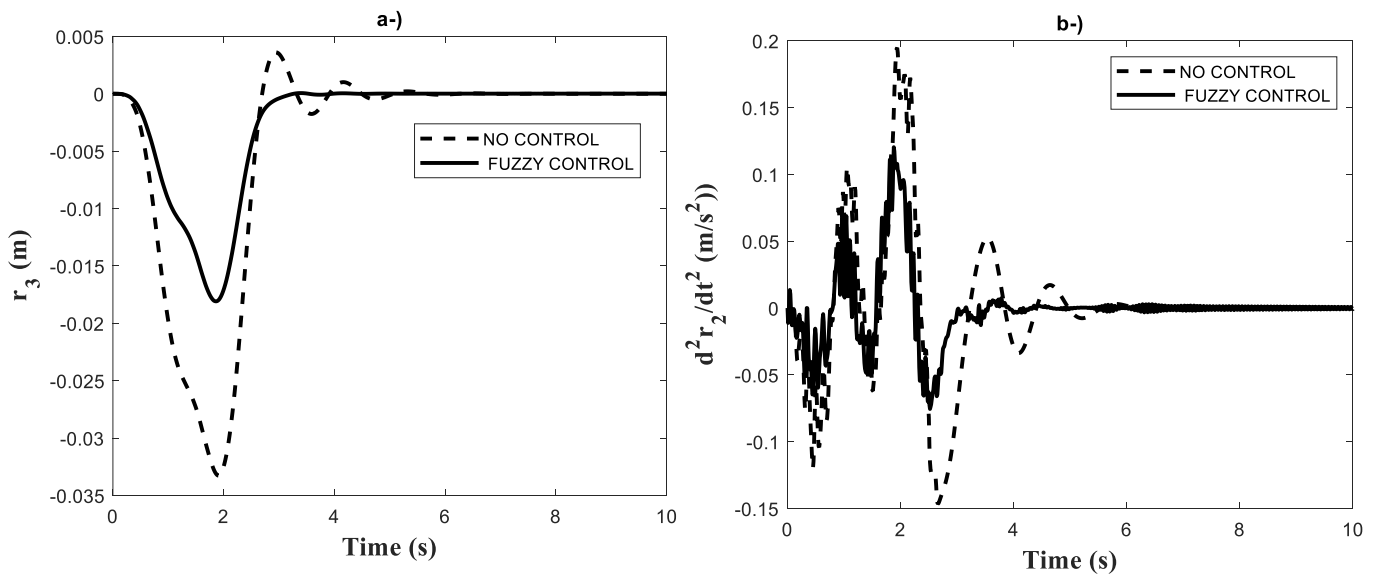

Figure 7. The train body vertical vibration with control and without control a-) train front bogie vertical displacements b-) train front bogie vertical acceleration. 

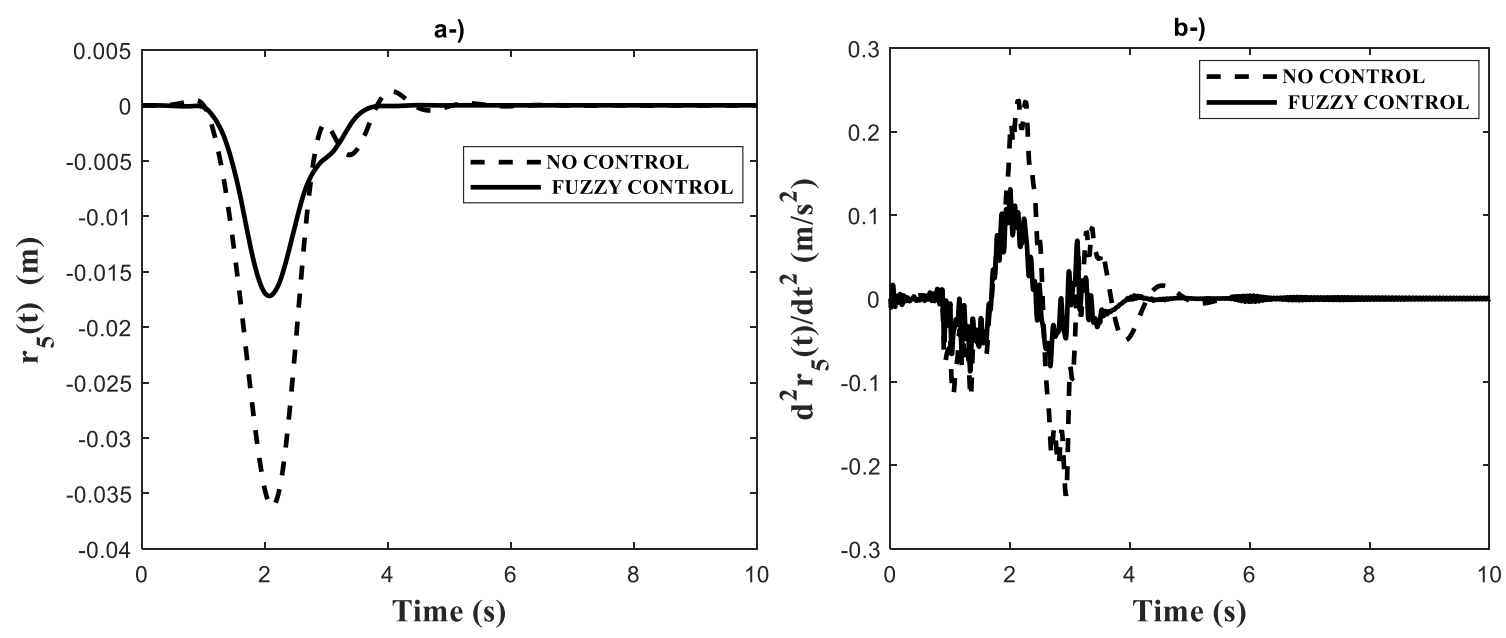

Figure 8. The train body vertical vibration with control and without control a-) rear bogie vertical displacements b-) rear bogie vertical acceleration.

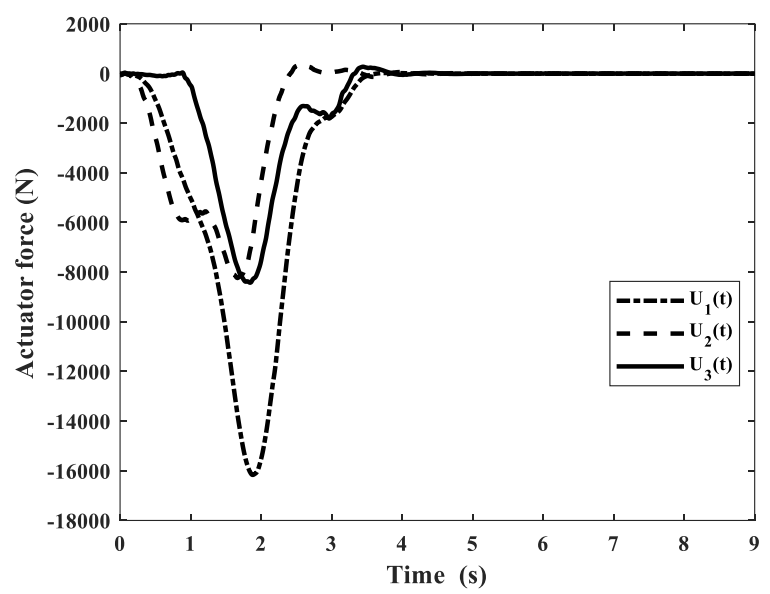

Figure 9. The actuator forces of the active suspension system generated by fuzzy logic controller.

\section{Conclusions}

The train bridge interaction is very complex engineering problem affected by many physical parameters for train and bridge. The excessive vibration caused by TBI negatively affects riding comfort and riding safety. Therefore, these vibrations should be reduced with passive and active suspension systems. The active suspension system is more effective in term of vibration reducing capability. In this study, it is proven that the active suspension system reduces vibrations about 50 percent due to TBI. But on the other hand, the biggest obstacle to using active suspension in HST is the high set up cost. Therefore, using mathematical foundation given by in this study, one can develops easily low-cost active suspension system in future works. 


\section{References}

[1] J. Han, Y. Hayashi, P. Jia, Q. Yuan, Economic Effect of High-Speed Rail: Empirical Analysis of Shinkansen's Impact on Industrial Location, J. Transp. Eng. 138 (2012) 15511557. https://doi.org/10.1061/(ASCE)TE.1943-5436.0000467.

[2] X. Jin, A measurement and evaluation method for wheel-rail contact forces and axle stresses of high-speed train, Measurement. 149 (2020) 106983. https://doi.org/10.1016/J.MEASUREMENT.2019.106983.

[3] M.-K. Song, H.-C. Noh, C.-K. Choi, A new three-dimensional finite element analysis model of high-speed train-bridge interactions, Eng. Struct. 25 (2003) 1611-1626. https://doi.org/10.1016/S0141-0296(03)00133-0.

[4] J.D. Yau, M.D. Martínez-Rodrigo, A. Doménech, An equivalent additional damping approach to assess vehicle-bridge interaction for train-induced vibration of short-span railway bridges, Eng. Struct. 188 (2019) 469-479. https://doi.org/10.1016/j.engstruct.2019.01.144.

[5] K. Youcef, T. Sabiha, D. El Mostafa, D. Ali, M. Bachir, Dynamic analysis of train-bridge system and riding comfort of trains, J. Mech. Sci. Technol. 27 (2013) 951-962. https://doi.org/10.1007/s12206-013-0206-8.

[6] B. Biondi, G. Muscolino, A. Sofi, A substructure approach for the dynamic analysis of train-track-bridge system, Comput. Struct. 83 (2005) 2271-2281. https://doi.org/10.1016/j.compstruc.2005.03.036.

[7] M. Majka, M. Hartnett, Effects of speed, load and damping on the dynamic response of railway bridges and vehicles, Comput. Struct. 86 (2008) 556-572. https://doi.org/10.1016/j.compstruc.2007.05.002.

[8] M. Valášek, W. Kortüm, Z. Šika, L. Magdolen, O. Vaculín, Development of semi-active road-friendly truck suspensions, Control Eng. Pract. 6 (1998) 735-744. https://doi.org/10.1016/S0967-0661(98)00079-3.

[9] J.F. Wang, C.C. Lin, B.L. Chen, Vibration suppression for high-speed railway bridges using tuned mass dampers, Int. J. Solids Struct. 40 (2003) 465-491. https://doi.org/10.1016/S0020-7683(02)00589-9.

[10] Z.Y. Gao, B. Tian, D.P. Wu, Y.S. Chang, Study on semi-active control of running stability in the high-speed train under unsteady aerodynamic loads and track excitation, Veh. Syst. Dyn. (2019) 1-14. https://doi.org/10.1080/00423114.2019.1662924.

[11] M.J. Thoresson, P.E. Uys, P.S. Els, J.A. Snyman, Efficient optimisation of a vehicle suspension system, using a gradient-based approximation method, Part 1: Mathematical modelling, Math. Comput. Model. 50 (2009) 1421-1436.

https://doi.org/10.1016/j.mcm.2009.07.011. 
[12] P.E. Uys, P.S. Els, M. Thoresson, Suspension settings for optimal ride comfort of off-road vehicles travelling on roads with different roughness and speeds, J. Terramechanics. 44 (2007) 163-175. https://doi.org/10.1016/j.jterra.2006.05.002.

[13] S.K. Sharma, A. Kumar, Ride comfort of a higher speed rail vehicle using a magnetorheological suspension system, Proc. Inst. Mech. Eng. Part K J. Multi-Body Dyn. 232 (2018) 32-48. https://doi.org/10.1177/1464419317706873.

[14] Q. Zhu, L. Li, C.J. Chen, C.Z. Liu, G. Di Hu, A Low-Cost Lateral Active Suspension System of the High-Speed Train for Ride Quality Based on the Resonant Control Method, IEEE Trans. Ind. Electron. 65 (2018) 4187-4196.

https://doi.org/10.1109/TIE.2017.2767547.

[15] M.A. Koç, İ. Esen, Modelling and analysis of vehicle-structure-road coupled interaction considering structural flexibility, vehicle parameters and road roughness $\dagger$, J. Mech. Sci. Technol. 31 (2017) 1-18. https://doi.org/10.1007/s12206-017-0913-y. 